\title{
Sequential E2 levels not ovarian maximal diameter estimates were correlated with outcome of cetrotide therapy for management of women at high-risk of ovarian hyperstimulation syndrome: a randomized controlled study
}

\author{
Khalid M. Salama*, Hesham M. Abo Ragab, Mohammed F. El Sherbiny, Ali A. Morsi and Ibrahim I. Souidan
}

\begin{abstract}
Background: Ovarian hyperstimulation syndrome (OHSS) is an important condition with considerable morbidity and a small risk of mortality and most commonly results as an iatrogenic condition following follicular stimulation of the ovaries. We aimed to evaluate safety and efficacy of 3-day cetrotide therapy started on day of oocyte retrieval (Day-0) in women at high-risk for development of ovarian hyperstimulation syndrome (OHSS) after GnRH agonist induction protocol.

Methods: Forty-eight women fulfilling inclusion criteria underwent ultrasound scanning for maximal ovarian diameter (MOD) estimation and ascites grading. Patients underwent embryo freezing, but the study group received 3-day Cetrotide sc injection ( $0.25 \mathrm{mg} /$ day) started on Day- 0 . Serum E2, pain scores and MOD were checked daily. Hematocrite value ( $\mathrm{Ht} \%)$, total leucocytic count (TLC), gastrointestinal (GI) manifestations and ascites grading were re-evaluated on Day-3, 6 and 8.

Results: Sequential serum E2 levels decreased significantly in both groups with significantly lower levels in the study group. Sequential MOD estimates showed non-significant difference between the two groups and versus Day-0 estimates. On Day-2, pain scores showed progressive significant decrease compared to Day-0 scores in both groups with significantly lower scores in the study group. On Day-3; four control patients still had vomiting and by Day- 6,6 of the control patients still had GI manifestations with significant difference versus the study group. Compared to Day-0 estimates, $\mathrm{Ht} \%$ and TLC were significantly lower on Day-3, 6 and 8 in the study group, but only on Day-8 in the control group. Day-3 and Day-8 ascites grading in both groups was significantly lower compared to respective Day-0 grading with significant difference in favor of the study group. Six patients required hospitalization, but without mortalities. Day-3 E2 levels in the study group showed positive significant correlation with clinical and other laboratory data and ascites grading, while the correlation was non-significant with MOD.
\end{abstract}

Conclusion: The 3-day cetrotide therapy starting after oocyte retrieval with embryo transfer freezing could be an appropriate management policy for women received GnHR-agonist induction protocol and were at high-risk for OHSS. Sequential E2 serum levels could predict outcome more perfectly than sequential MOD estimates.

Trial registration: Trial registration (clinicaltrial.gov registration) NCT02823080 (retrospective) Initial Release 21-6-2016 Last Release 3-1-2017 Unique Protocol ID: Benha U Secondary IDs: kmsalama.

Keywords: Ovarian hyper stimulation syndrome, Cetrotide therapy, Embryo freezing

\footnotetext{
* Correspondence: dr.khalid_sleem@yahoo.com

Department of Obstetrics and Gynecology, Faculty of Medicine, Benha

University, Benha, Egypt
} 


\section{Background}

Ovarian hyperstimulation syndrome (OHSS) is a disease state that occur secondary to ovarian stimulation in which ovaries were enlarged with fluid transudation into body spaces and subsequent reduction of circulatory volume that may predispose to increased risk of venous thrombosis and decreased organ perfusion [1]. Multiple predisposing factors were supposed for the possibility of developing OHSS during ovarian stimulation protocols. Age, antral follicles count, infertility cause, hypothyroidism and positive history of ovarian surgery were the most important predictors of OHSS, but the number of follicles and serum estradiol level on human chorionic gonadotropin day were the strongest predictive variables [2].

For prophylaxis against development of OHSS, multiple trials compared gonadotropin-releasing hormone (Gn-RH) agonist (GnRH-a) versus $\mathrm{Gn}-\mathrm{RH}$-antagonist (GnRH-ant) induction protocols wherein Kdous et al. [3] found GnRH-ant allows a higher flexibility in treatment, a lower dose of follicle stimulating hormone (FSH) was required and a shorter period of stimulation with no case of OHSS versus 3\% with GnRH-a therapy. Martínez et al. [4] found stimulation protocol based on gonadotropins and a single dose of cetrorelix acetate $3 \mathrm{mg}$ was adequate in terms of safety and Depalo et al. [5] also documented that protocols with GnRH-ant were effective in preventing a premature rise of $\mathrm{LH}$ and induced a shorter and more cost-effective ovarian stimulation compared to the long agonist protocol.

Various drugs were evaluated for the prevention or treatment of OHSS; experimentally, in rat model of OHSS, both myo-inositol and metformin reduced vascular endothelial growth factor (VEGF) and COX-2 expressions with decreased vascular permeability and blood E2 levels in the groups treated with myo-inositol or metformin compared to the OHSS group [6]. Another experimental animal trial reported that letrozole and cabergoline were equally effective to prevent OHSS, reducing the ovarian diameter, vascular permeability, pigment epithelium-derived factor (PEDF) and VEGF levels to similar extents [7]. Turan et al. [8] experimentally found prophylactic vitamin D supplementation effectively increases PEDF, but is not sufficiently effective in preventing OHSS. Clinically, Kılıç et al. [9] found prophylactic treatment with the dopamine agonist, cabergoline, reduced the incidence of OHSS in women at high risk undergoing IVF/ICSI treatment, but the effects of cabergoline on live birth, miscarriage, and congenital abnormalities are still uncertain.

The current prospective comparative study aimed to evaluate the efficacy of the 3-day cetrotide therapy starting on the day of oocyte retrieval in women at high-risk for development of OHSS after GnRH agonist induction protocol as judged by changes of serum E2 level and maximal ovarian diameter.

\section{Methods}

The current study was conducted at Assisted Reproduction Unit at Almana general, Hospital, KSA and some private centers in Egypt. The study protocol was approved by the Local Ethical Committee. The study was started from October 2014 till August 2016. The study aimed to include women suspected to be at high risk for development of OHSS during agonist ovarian stimulation protocol. Inclusion criteria included the number of retrieved oocytes must be $\geq 20$; mean number of follicles with a diameter of $>16 \mathrm{~mm}$ was $\geq 18$; serum E2 concentrations of $\geq 3500 \mathrm{pg} / \mathrm{ml}$; ovarian diameter on the day of ovum retrieval of $>10 \mathrm{~cm}$; and presentation of evident symptoms of OHSS on the day of aspiration [10]. The study included only women of couples who singed written consent to participate in the study, to undergo embryo freezing and to postpone for transfer of cryopreserved embryo. Patients followed GnRH-antagonist protocol, or who had liver, hepatic, cardiac or pulmonary dysfunction, coagulation disorders, or refused to sign the consent were excluded from the study.

All patients were clinically evaluated for the presence of abdominal pain and if present, it was graduated using a numerical pain visual analogue scale (VAS) with 0 means no pain and 10 means severe intolerable pain [11]. Patients were evaluated for the presence of nausea and/or vomiting; nausea was defined as the unpleasant sensation associated with awareness of the urge to vomit and was scored as $0=$ nil, $1=$ mild, $2=$ moderate, and $3=$ severe nausea. Vomiting was defined as the forceful expulsion of gastric contents from the mouth and was scored as $0=$ nil, $1=$ one mouthful, and $2=$ more than one mouthful of vomitus [12]. Sense of abdominal distension was scored using verbal analogue scale as nil, mild, moderate, and severe distension. Blood samples were obtained under complete aseptic condition for estimation of serum E2 level and determination of hematocrit value $(\mathrm{Ht} \%)$ and total leucocytic count (TLC).

Then, all patients underwent ultrasound scanning for estimation of ovarian measurements that were represented as the maximal ovarian diameter (MOD) and for ascites grading if present. Ultrasound scanning was performed using a $5 \mathrm{MHz}$ vaginal probe (probe EC4 accuvix), otherwise a $3.5 \mathrm{MHz}, 2.6 \mathrm{MHz}$ or $5 \mathrm{MHz}$ abdominal probe (probe C3-71 M accuvix) was used if visualization using a vaginal probe was compromised. Ascites was graded according to the quantity of fluid accumulation in the peritoneal cavity with the patient in the anti-Trendelenburg position according to Lainas et al. [13]. 
All women fulfilling inclusion criteria were graded, as regards the severity of OHSS manifestations, according to classification grading of OHSS proposed by Navot et al. [14]. All patients followed cancellation embryo replacement and embryo freezing protocol and were randomly allocated, using sealed envelops, into two equal groups. Control group included women received traditional symptomatic treatment including analgesics, antispasmodics and antiemetic therapy. Study group received, in addition to symptomatic treatment, cetrotide subcutaneous injection (cetrorelix acetate, Merk Serono, UK) in a daily dose of $0.25 \mathrm{mg}$ according to Albano et al. [15] started on day of oocyte retrieval for 3 days.

All patients were managed as outpatients unless presented with severe manifestations necessitated hospital admission. Pain scores, serum E2 levels and MOD were evaluated daily. Patients were evaluated for associated symptoms previously determined during clinical evaluation, ascites grading and TLC and Ht value were evaluated at 3 and 6 days and on end of the trial on the 8th day after oocyte retrieval.

\section{Study outcome}

1. Primary outcome was defined as occurrence and extent of change of elevated blood E2 levels and change of MOD.

2. Secondary outcome was defined as resolution or diminution of clinical, other laboratory and US manifestations determined prior to start of therapy.

\section{Statistical analysis}

Obtained data were presented as mean $\pm \mathrm{SD}$, numbers and percentages. Results were analyzed using One-way ANOVA with post-hoc Tukey HSD Test and Chi-square test $\left(\mathrm{X}^{2}\right.$ test). Statistical analysis was conducted using the SPSS (Version 15, 2006) for Windows statistical package. $P$ value $<0.05$ was considered statistically significant.

\section{Results}

Fifty-seven patients at high-risk for developing OHSS were assessed for eligibility; 9 patients were excluded for being not fulfilling inclusion criteria, while 48 patients were randomized into two groups (Fig. 1).

Patients of both groups showed non-significant $(p>0.05)$ differences concerning demographic, ovarian stimulation data and OHSS-related data as shown in Tables 1 and 2 .

Throughout the observation period, estimated serum E2 levels showed progressive significant $(p<0.05)$ decline compared to Day-0 levels in patients of both groups with significantly $(\mathrm{p}<0.05)$ lower serum E2 levels estimated in patients of study group compared to patients of control group. Moreover, the percentages of decrease of estimated serum E2 levels during the follow-up period were progressively increasing in both groups but were significantly higher in patients of study compared to patients of control group (Fig. 2). Interestingly, mean MOD showed gradual non-significant $(p>0.05)$ decrease in patients of both groups compared to Day-0 MOD (Table 3).

Day-1 VAS pain scores were non-significantly $(p>0.05)$ decreased in both groups compared to Day-0 scores and to each other. In study group, on the 2 nd day, pain started

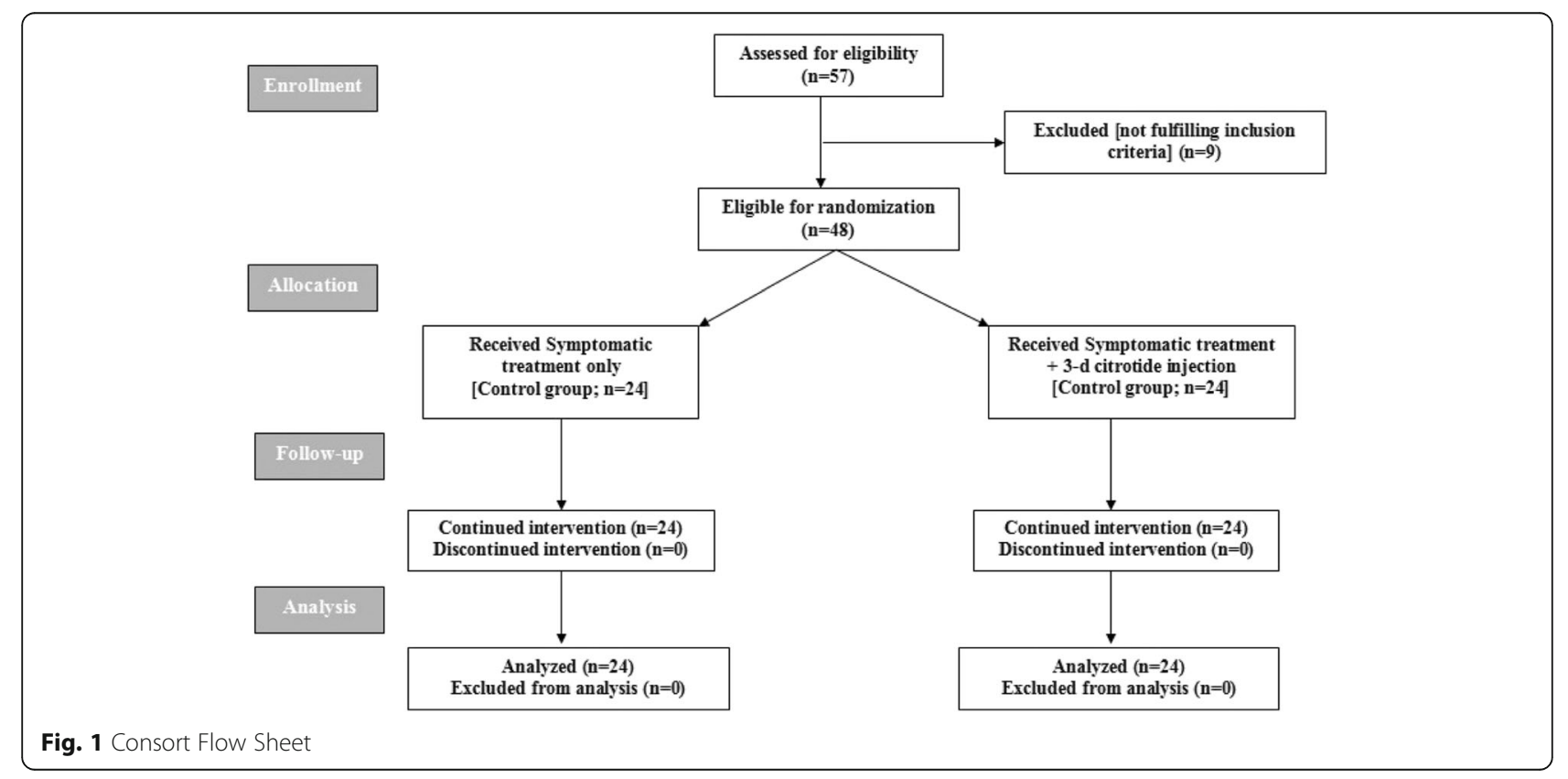


Table 1 Demographic and stimulation data of included patients

\begin{tabular}{|c|c|c|c|c|c|c|}
\hline \multicolumn{4}{|l|}{ Data } & \multirow{2}{*}{$\frac{\text { Control }}{6(25 \%)}$} & \multirow{2}{*}{$\frac{\text { Study }}{11(45.8 \%)}$} & \multirow{2}{*}{$\frac{P \text { value }}{>0.05}$} \\
\hline Age (years) & Strata & $\leq 25$ & & & & \\
\hline & & $26-30$ & & $11(45.8 \%)$ & $8(33.3 \%)$ & \\
\hline & & $>30$ & & $7(29.2 \%)$ & $5(20.9 \%)$ & \\
\hline & Total & & & $28.6 \pm 3.3$ & $27 \pm 4$ & $>0.05$ \\
\hline \multirow[t]{6}{*}{ BMI data } & Weight (kg) & & & $78 \pm 6.1$ & $80.5 \pm 7.7$ & $>0.05$ \\
\hline & Height (cm) & & & $168 \pm 3.6$ & $167 \pm 4.2$ & $>0.05$ \\
\hline & BMI $\left(\mathrm{kg} / \mathrm{m}^{2}\right)$ & Strata & $<25$ & $6(25 \%)$ & $3(12.5 \%)$ & $>0.05$ \\
\hline & & & $25-30$ & $14(58.3 \%)$ & $12(50 \%)$ & \\
\hline & & & $>30$ & $4(16.7 \%)$ & $9(37.5 \%)$ & \\
\hline & & Total & & $27.6 \pm 2.4$ & $28.9 \pm 2.9$ & $>0.05$ \\
\hline \multirow[t]{3}{*}{ Duration of infertility } & Strata & $\leq 5$ & & 7 (29.2\%) & $8(33.3 \%)$ & $>0.05$ \\
\hline & & $>5$ & & $17(70.8 \%)$ & $16(66.7 \%)$ & \\
\hline & Total & & & $3.8 \pm 2$ & $4.2 \pm 2.1$ & \\
\hline \multirow[t]{3}{*}{ Cause of infertility } & Male factor & & & $11(45.8 \%)$ & $10(41.6 \%)$ & $>0.05$ \\
\hline & Female factor & & & $5(20.9 \%)$ & 7 (29.2\%) & \\
\hline & Mixed & & & $8(33.3 \%)$ & $7(29.2 \%)$ & \\
\hline \multirow[t]{2}{*}{ PCOS } & Yes & & & $20(83.3 \%)$ & 19 (79.1\%) & $>0.05$ \\
\hline & No & & & $4(16.7 \%)$ & $5(20.9 \%)$ & \\
\hline \multicolumn{4}{|l|}{ Basal FSH (mIU/ml) } & $7.5 \pm 1$ & $7.31 \pm 0.77$ & $>0.05$ \\
\hline \multicolumn{4}{|c|}{ Total gonadotrophin dose (IU/ml) } & $1605 \pm 404$ & $1475.4 \pm 382$ & $>0.05$ \\
\hline \multicolumn{4}{|c|}{ Time of stimulation (days) } & $8.1 \pm 1.4$ & $8.2 \pm 1.6$ & $>0.05$ \\
\hline \multicolumn{4}{|l|}{ HCG dose (IU/ml) } & $5800 \pm 1500$ & $5977 \pm 1788$ & $>0.05$ \\
\hline
\end{tabular}

Data are presented as mean \pm SD \& numbers; percentages are in parenthesis

Table 2 OHSS-related clinical and laboratory data

\begin{tabular}{|c|c|c|c|c|c|c|}
\hline & Control & Study & $P$ value \\
\hline \multicolumn{4}{|c|}{ Number of retrieved oocytes } & $20.4 \pm 1.6$ & $21.1 \pm 1.7$ & $>0.05$ \\
\hline \multicolumn{4}{|c|}{ Number of follicles (diameter of $>16$ mm) } & $17.1 \pm 2.6$ & $18 \pm 3.2$ & $>0.05$ \\
\hline \multicolumn{4}{|c|}{ Serum E2 concentrations ( $\mathrm{pg} / \mathrm{ml}$ ) } & $5004 \pm 792$ & $4761 \pm 940$ & $>0.05$ \\
\hline \multicolumn{4}{|c|}{ Ovarian maximum diameter (mm) } & $10.4 \pm 5.8$ & $9.4 \pm 4.5$ & $>0.05$ \\
\hline \multirow{3}{*}{\multicolumn{2}{|c|}{ Frequency of associated symptoms }} & \multicolumn{2}{|c|}{ Distension } & $19(79.2 \%)$ & $20(83.3 \%)$ & $>0.05$ \\
\hline & & \multicolumn{2}{|c|}{ Nausea } & $19(79.2 \%)$ & $18(75 \%)$ & $>0.05$ \\
\hline & & \multicolumn{2}{|c|}{ Vomiting } & $10(41.7 \%)$ & $12(50 \%)$ & $>0.05$ \\
\hline \multirow[t]{8}{*}{ Laboratory findings } & Ht value $(\%)$ & \multirow[t]{3}{*}{ Strata } & $<40$ & $14(58.3 \%)$ & $17(70.8 \%)$ & \multirow[t]{3}{*}{$>0.05$} \\
\hline & & & $40-45$ & $6(25 \%)$ & $6(25 \%)$ & \\
\hline & & & $>45$ & $4(16.7 \%)$ & $1(4.2 \%)$ & \\
\hline & & \multicolumn{2}{|c|}{ Mean value } & $39.8 \pm 4.2$ & $42.2 \pm 5.2$ & $>0.05$ \\
\hline & \multirow[t]{4}{*}{ TLC $\left(\times 10^{3}\right.$ cells $\left./ \mathrm{ml}\right)$} & \multirow[t]{3}{*}{ Strata } & $<10$ & $4(16.7 \%)$ & $12(50 \%)$ & \multirow[t]{3}{*}{$>0.05$} \\
\hline & & & $10-15$ & 14 (58.3\%) & 8 (33.3\%) & \\
\hline & & & $>15$ & $6(25 \%)$ & $4(16.7 \%)$ & \\
\hline & & Mean & & $11.6 \pm 3.7$ & $12.75 \pm 3.1$ & $>0.05$ \\
\hline \multirow[t]{3}{*}{ Ascites } & \multirow[t]{2}{*}{ US detected } & Low & & $6(25 \%)$ & 8 (33.3\%) & \multirow[t]{2}{*}{$>0.05$} \\
\hline & & Mode & & $18(75 \%)$ & $16(66.7 \%)$ & \\
\hline & \multicolumn{3}{|c|}{ Marked (Clinically detected) } & 0 & 0 & \\
\hline
\end{tabular}




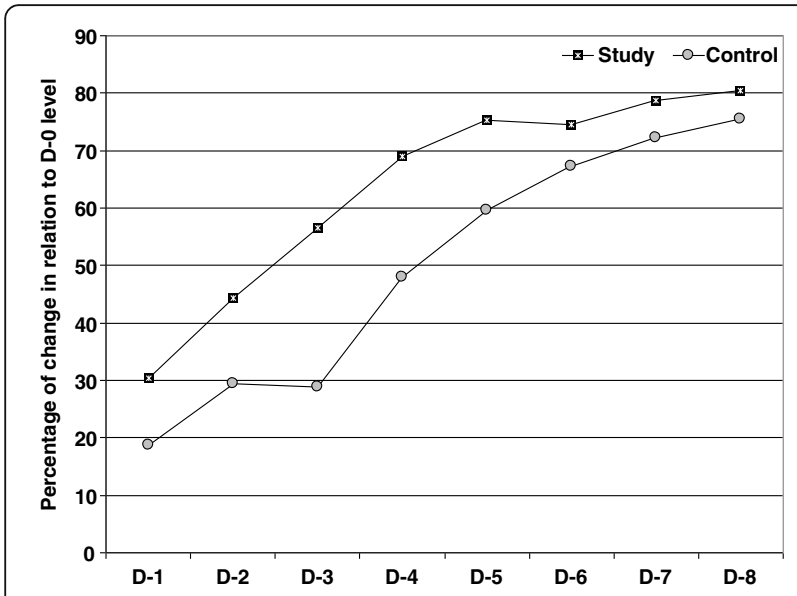

Fig. 2 Mean estimated serum E2 levels during follow-up period

to be alleviated and scores showed progressive $(p<0.05)$ significant decrease compared to Day-0 scores and to control group. On contrary, pain scores of patients in control group were non-significantly decreased since Day-2 till Day- 4 , but significantly decreased thereafter till Day- 8 in comparison to Day-0 scores (Table 4).

Concerning gastrointestinal (GI) manifestations; at Day-0, 37 patients had nausea, 22 patients had vomiting and 39 patients had abdominal distension of varying severity with non-significant $(p>0.05)$ difference between both groups. Nine patients had severe nausea and one of them had severe vomiting, while 5 patients had severe abdominal distension. On Day-3; 17 patients had nausea, 4 patients had vomiting and 24 patients still had abdominal distension; all of still complaining patients were of mild or moderate severity grades. As regards vomiting no patient in study group, while 4 patients in control group still had liability to vomit with significant $(p<0.05)$ difference in favor of study group. On contrary, the frequency of patients still had nausea and abdominal distension was non-significantly ( $p>$ $0.05)$ lower in study group compared to control group. By the 6th day, 6 patients in control group still had GI manifestations with significant $(p<0.05)$ difference versus study group. However, by the 8th day, all patients were free of GI manifestations (Table 5).

Mean Ht value and TLC showed progressive decline throughout the observation period with non-significant $(p>0.05)$ difference between both groups. However, in comparison to Day-0 levels, estimated Ht value and TLC were significantly $(p<0.05)$ lower at Day-3, 6 and 8 in study group while in control group the difference was significant $(p<0.05)$ only in Day-8 estimates (Table 6).

On Day-0, no patient developed marked ascites, 34 patients had moderate and 14 patients had mild ascites with non-significant $(p>0.05)$ difference between both groups. On Day-3, three patients in control group developed marked (clinically detected) ascites, 14 patients had moderate and 31 patients had mild ascites. On Day-3 patients' distribution among ascites severity grades showed significant $(p<0.05)$ difference in both groups compared to the respective Day-0 distribution with significant difference in favor of study group. Two patients in control group with marked ascites were admitted to the hospital for paracentesis on Day-4 and Day-5, while the 3rd patient showed gradual resolution to moderate ascites on Day-8. On Day-8, patients' distribution among ascites severity grades showed significant $(p<0.05)$ difference compared to Day-0 distribution in both groups and in study group compared to Day- 8 distribution in control group (Table 7).

Five patients $(20.9 \%)$ required hospitalization; 4 patients in control group and one patient in the study group with non-significantly $(p>0.05)$ lower frequency of hospitalization in the study group. Two patients had severe distension and one had severe nausea and vomiting. These three patients received ondansetron antiemetic

Table 3 Serum E2 levels and maximal ovarian diameter (MOD) of studied patients estimated throughout the observation period in both groups

\begin{tabular}{|c|c|c|c|c|c|c|}
\hline & \multicolumn{3}{|c|}{ Serum E2 level (pg/ml) } & \multicolumn{3}{|c|}{ Maximal ovarian diameter (mm) } \\
\hline & Control & Study & $P$ value & Control & Study & $P$ value \\
\hline Day-0 & $5004 \pm 792$ & $4761 \pm 940$ & $>0.05$ & $10.4 \pm 5.8$ & $9.4 \pm 4.5$ & $>0.05$ \\
\hline Day-1 & $4212 \pm 950^{a}$ & $3397 \pm 1361^{a}$ & 0.021 & $10.2 \pm 5.6$ & $9.3 \pm 4.6$ & $>0.05$ \\
\hline Day-2 & $3620 \pm 1037^{a}$ & $2772 \pm 1456^{a}$ & 0.011 & $9.6 \pm 4.6$ & $9.1 \pm 4.2$ & $>0.05$ \\
\hline Day-3 & $3592 \pm 862^{\mathrm{a}}$ & $2067 \pm 900^{\mathrm{a}}$ & 0.005 & $9.4 \pm 4.9$ & $8.7 \pm 4.3$ & $>0.05$ \\
\hline Day-4 & $2570 \pm 914^{a}$ & $1452 \pm 617^{a}$ & 0.007 & $9.2 \pm 4.7$ & $8.5 \pm 4.3$ & $>0.05$ \\
\hline Day-5 & $1914 \pm 965^{a}$ & $1173 \pm 180^{a}$ & 0.003 & $9 \pm 4.6$ & $7.8 \pm 4$ & $>0.05$ \\
\hline Day-6 & $1544 \pm 812^{\mathrm{a}}$ & $1173 \pm 180^{\mathrm{a}}$ & 0.006 & $8.5 \pm 4.6$ & $7.5 \pm 4.2$ & $>0.05$ \\
\hline Day-7 & $1275 \pm 588^{\mathrm{a}}$ & $969 \pm 118^{\mathrm{a}}$ & 0.001 & $8.2 \pm 4.5$ & $7.3 \pm 4$ & $>0.05$ \\
\hline Day-8 & $1044 \pm 200^{a}$ & $902 \pm 66^{a}$ & 0.001 & $7.9 \pm 4.2$ & $7.1 \pm 3.7$ & $>0.05$ \\
\hline
\end{tabular}

Data are presented as mean $( \pm \mathrm{SD})$; Day-0: time of enrolment; ${ }^{\mathrm{a}}$ : significant difference versus respective Day- 0 data; $P$ value for the difference between both groups 
Table 4 Mean pain VAS score determined throughout the observation period in both groups

\begin{tabular}{llll}
\hline & Control & Study & $P$ value \\
\hline Day-0 & $5.4 \pm 1.7$ & $5.3 \pm 1.6$ & $>0.05$ \\
Day-1 & $5 \pm 1.3$ & $4.3 \pm 1.3^{\mathrm{a}}$ & 0.045 \\
Day-2 & $4.9 \pm 1.8$ & $3.6 \pm 1^{\mathrm{a}}$ & 0.003 \\
Day-3 & $4.6 \pm 1.8$ & $2.3 \pm 1.8^{\mathrm{a}}$ & 0.001 \\
Day-4 & $4.5 \pm 1.4$ & $1.6 \pm 1.2^{\mathrm{a}}$ & 0.001 \\
Day-5 & $3.7 \pm 2^{\mathrm{a}}$ & $0.92 \pm 1.1^{\mathrm{a}}$ & 0.001 \\
Day-6 & $2.4 \pm 1.1^{\mathrm{a}}$ & $0.33 \pm 0.6^{\mathrm{a}}$ & 0.001 \\
Day-7 & $1.6 \pm 1.1^{\mathrm{a}}$ & $0.17 \pm 0.38^{\mathrm{a}}$ & 0.001 \\
Day-8 & $1.1 \pm 1.7^{\mathrm{a}}$ & $0.13 \pm 0.34^{\mathrm{a}}$ & 0.001 \\
\hline
\end{tabular}

Data are presented as mean $( \pm S D)$; Day-0: time of enrolment; ${ }^{a}$ : significant difference versus respective Day- 0 data; $P$ value for the difference between both groups

therapy in dose of $40 \mathrm{mg}$ ampoule twice daily and crystalloid replacement fluid therapy. No other complications were encountered in patients of both groups.

There was positive significant $(p<0.05)$ correlation between Day-3 serum E2 level and clinical and other laboratory findings and ascites grading in the study group determined on Day-3. On contrary, Day-3 MOD showed non-significant $(p>0.05)$ positive correlation with these parameters and with Day-3 serum E2 levels.

\section{Discussion}

Both therapeutic policies did favorably for patients received GnRH-a protocol and were at high-risk for development of OHSS. Such effect was manifested as reduction of hospitalization rate down to $16.7 \%$; thus establishing the feasibility of outpatient management of such cases and abolished the development of marked ascites that was developed in three patients in control group and required paracentesis to manage two cases.

Despite the favorable outcome of both groups, addition of cetrotide sc injection for three days to embryo freezing improved outcome of patients in the study group manifested as significant reduction of serum E2 and pain scores on daily assessment with significant reduction of frequency and severity of GI manifestations and ascites on Day-3 compared to patients received embryo freezing only.

In line with the effectiveness of $\mathrm{GnRH}$ antagonist (cetrotide) therapy for control of frequency and severity of OHSS in high-risk women received GnRH-a induction protocol; Bonilla-Musoles et al. [16] reported that compared to controls, treatment with $3 \mathrm{mg}$ cetrotide seems to be effective in the management of severe OHSS with significantly dropped E2 levels and faster peritoneal fluid regression as measured by US few days after treatment, and none of cetrorelix treated patients required paracentesis.

Hosseini et al. [17] reported that the frequency of moderate and severe OHSS, hospitalization or acute care for OHSS and ascites tap rates were significantly lower with significantly higher patients' satisfaction with cetrotide than in control group and concluded that GnRH antagonist cetrotide seems to be an effective outpatient treatment with rapid onset activity and minimal side effects for the management of early OHSS.

Lainas et al. [18] reported that low-dose luteal GnRHant administration in women with severe early OHSS is associated with significantly decreased ovarian volume, ascites, hematocrit, white blood cell count, serum estradiol and progesterone by the end of the day 11 post-oocyte retrieval, indicating rapid resolution of the severe OHSS.

Table 5 Patients' distribution among severity grades of Gl manifestations determined at Day-3 and Day-6 compared to Day-0 distribution in both groups

\begin{tabular}{|c|c|c|c|c|c|c|c|c|c|c|}
\hline \multirow[t]{2}{*}{ Symptom } & \multirow[t]{2}{*}{ Time } & \multicolumn{4}{|c|}{ Control } & \multicolumn{4}{|c|}{ Study } & \multirow[t]{2}{*}{$P$ value } \\
\hline & & Nil & Mild & Moderate & Severe & $\mathrm{Nil}$ & Mild & Moderate & Severe & \\
\hline \multirow[t]{4}{*}{ Nausea } & Day-0 & 6 & 7 & 6 & 5 & 5 & 8 & 7 & 4 & $>0.05$ \\
\hline & Day-3 & 12 & 8 & 4 & 0 & 19 & 4 & 1 & 0 & $>0.05$ \\
\hline & Day-6 & 22 & 2 & 0 & 0 & 24 & 0 & 0 & 0 & 0.047 \\
\hline & Day-8 & 24 & 0 & 0 & 0 & 24 & 0 & 0 & 0 & $>0.05$ \\
\hline \multirow[t]{4}{*}{ Vomiting } & Day-0 & 12 & 8 & 4 & 0 & 14 & 7 & 2 & 1 & $>0.05$ \\
\hline & Day-3 & 20 & 4 & 0 & 0 & 24 & 0 & 0 & 0 & 0.037 \\
\hline & Day-6 & 24 & 0 & 0 & 0 & 24 & 0 & 0 & 0 & $>0.05$ \\
\hline & Day-8 & 24 & 0 & 0 & 0 & 24 & 0 & 0 & 0 & $>0.05$ \\
\hline \multirow[t]{4}{*}{ Abdominal distension } & Day-0 & 4 & 7 & 10 & 3 & 5 & 8 & 9 & 2 & $>0.05$ \\
\hline & Day-3 & 9 & 12 & 3 & 0 & 15 & 8 & 1 & 0 & $>0.05$ \\
\hline & Day-6 & 20 & 4 & 0 & 0 & 24 & 0 & 0 & 0 & 0.037 \\
\hline & Day-8 & 24 & 0 & 0 & 0 & 24 & 0 & 0 & 0 & $>0.05$ \\
\hline
\end{tabular}


Table 6 Mean Ht value and TLC estimated throughout the observation period in both groups

\begin{tabular}{llllll}
\hline & \multicolumn{2}{l}{ Ht value (\%) } & & \multicolumn{2}{c}{ TLC $\left(10^{3} / \mathrm{ml}\right)$} \\
\cline { 2 - 3 } & Control & Study & & Control & Study \\
\hline Day-0 & $39.8 \pm 4.2$ & $42.2 \pm 5.2$ & & $11.6 \pm 3.7$ & $12.75 \pm 3.1$ \\
Day-3 & $38.8 \pm 3.3$ & $38.7 \pm 3.3^{\mathrm{a}}$ & & $11.3 \pm 3.6$ & $11.5 \pm 2.8^{\mathrm{a}}$ \\
Day-6 & $38 \pm 3.1$ & $37.3 \pm 2.5^{\mathrm{a}}$ & & $11.2 \pm 3.6$ & $11 \pm 1.9^{\mathrm{a}}$ \\
Day-8 & $37.5 \pm 1.5^{\mathrm{a}}$ & $36.8 \pm 2.6^{\mathrm{a}}$ & & $10.1 \pm 2.2^{\mathrm{a}}$ & $9.75 \pm 3.1^{\mathrm{a}}$ \\
\hline
\end{tabular}

Data are presented as mean $( \pm \mathrm{SD}) ;{ }^{\text {a }}$ : significant difference versus respective Day-0 data

Thereafter, Lainas et al. [19] reported improvement of ultrasound and laboratory parameters, indicating regression of severe OHSS, 7-days after start of GnRH antagonist therapy. Recently, Hebisha et al., [20] documented that $\mathrm{GnRH}$ antagonist administration on the day of hCG in cases undergoing IVF/ICSI with long agonist protocol is effective in protection of OHSS and does not affect the clinical pregnancy rate or live birth rate.

The current study detected a relation between the results of sequential estimation of serum E2 and outcome manifested as scorings of pain, associated GI manifestations and severity of ascites. Interestingly, sequential estimation of maximal ovarian diameter did not show significant reduction in either group or relation with these parameters. Such discrepancy between serum E2 levels and ovarian maximal diameter may be attributed to the multiplicity of mechanisms underlying development and progression of OHSS and so for its regression. Similarly, Jakimiuk et al. [21] documented that OHSS is still a difficult diagnostic and therapeutic problem, more studies are required to elucidate pathophysiology of OHSS and because of still unknown etiology treatment is empirical.

In support of the multiplicity of underlying pathophysiological mechanisms for development of OHSS, multiple experimental and clinical trials are still trying to explore these mechanisms. Experimentally, Bar-Joseph et al. [22] demonstrated that pigment epitheliumderived factor (PEDF), a novel intrinsic antioxidant of granulosa cells, possesses potent physiologic anti-angiogenic activity that negates VEGF activity and Chuderland et al. [23] shown that expression of PEDF in granulosa cell line is regulated by hCG, reciprocally to VEGF, and that the PEDF-VEGF balance is impaired in OHSS. Thereafter, Miller et al. [24] using rat model found the severity of OHSS is correlated with hCG-induced PEDFVEGF ovarian expression impaired ratio.

In 2016, Bar-Joseph et al. [25] found that hCG-induced PEDF down-regulation and VEGF up-regulation are mediated by signaling cascades, as protein kinase A, protein kinase $C$, epidermal growth factor receptor, which emphasizes the delicate regulation of ovarian angiogenesis. Lunger et al. [26] reported the presence of main opiate receptor-1 (OPRM1) on human granulosa cells and found its blocking significantly reduced granulosa cellderived VEGF levels in granulosa-luteal cells; thus raising a possibility of disturbed ovarian levels of growth factors as basis for development of OHSS; irrespective of the receptor-type for initiation of response.

On the other side, Orvieto et al. [27] provided a firm evidence for the presence of interleukin (IL)-2 and IL-2 mRNA expression in luteinized granulosa cells of the hyperstimulated human ovaries and suggested that IL-2 could activate the systemic inflammatory response characteristic of OHSS. Taskin et al. [28] detected significantly lower ovarian weight, estrogen levels and corpus luteum counts with lower IL-6 intensity and VEGF expression in $\mathrm{GnRH}$ antagonist treated animals than in OHSS animals and attributed development of OHSS to increased expression of VEGF secondary to increased IL-6 intensity; thus raising a possibility of inflammatory basis for development of OHSS.

Clinically, Lainas et al. [19] reported significant decline of VEGF 7-days after start of GnRH antagonist therapy and this decline was associated with an improvement of ultrasound and laboratory parameters, indicating regression of severe OHSS.

Delabaere et al. [29] and Langroudi et al. [30] reported spontaneous OHSS during pregnancy in a context of moderate hypothyroidism and supposed that the etiology of spontaneous OHSS should seek hypersecretion of glycoprotein hormones (hCG, TSH, FSH and LH) and/or mutation of FSH and LH receptors; thus raising a possibility of endocrinal basis for development of OHSS.

Orkunoglu-Suer et al. [31] using polymerase chain reaction captured a non-synonymous LH CG-single

Table 7 Patients' distribution among severity grades of ascites determined at Day-3 and Day-8 compared to Day-0 distribution in both groups

\begin{tabular}{|c|c|c|c|c|c|c|c|}
\hline \multirow{2}{*}{$\begin{array}{l}\text { Time } \\
\text { Ascites severity }\end{array}$} & & \multicolumn{2}{|l|}{ Day-0 } & \multicolumn{2}{|l|}{ Day-3 } & \multicolumn{2}{|l|}{ Day-8 } \\
\hline & & Control & Study & Control & Study & Control & Study \\
\hline \multirow[t]{2}{*}{ US detected } & Low & $6(25 \%)$ & 8 (33.3\%) & $13(54.2 \%)^{a}$ & $18(75 \%)^{\mathrm{ab}}$ & $17(70.8 \%)^{\mathrm{a}}$ & $21(83.3 \%)^{\mathrm{ab}}$ \\
\hline & Moderate & $18(75 \%)$ & 16 (66.7\%) & 8 (33.3\%) & $6(25 \%)$ & $5(20.8 \%)$ & $3(16.7 \%)$ \\
\hline \multicolumn{2}{|c|}{ Marked (Clinically detected) } & 0 & 0 & $3(12.5 \%)$ & 0 & $2(8.4 \%)$ & 0 \\
\hline
\end{tabular}

Data are presented as numbers (\%); ${ }^{\text {a }}$ significant difference versus respective Day-0 data; ${ }^{\text {b}}$ : significant difference versus control group 
nucleotide polymorphism in two severe OHSS cases, and verified its presence by conventional sequencing; thus supposing underlying genetic basis for development of OHSS. Blumenfeld [32] reported that supra-physiological E2 level in OHSS may increase the growth hormone-binding protein (GH-BP) bio-neutralizing $\mathrm{GH}$ and diminishing the resultant insulin-like growth factor levels necessary for optimal synergism with FSH.

\section{Conclusion}

Three-day cetrotide therapy starting after oocyte retrieval with embryo freezing could be considered as an appropriate management policy for women received GnHR-agonist induction protocol and were at high-risk for OHSS development. Sequential E2 serum level estimations could predict outcome perfectly than sequential determination of maximal ovarian diameter.

\begin{abstract}
Abbreviations
CG: Cytosine guanine; COX-2: Cyclo-oxygenase 2; E2: Estradiol; FSH: Follicle stimulating hormone; GH-BP: Growth hormone-binding protein;

Gl: Gastrointestinal; GnRH-a: Gonadotropin-releasing hormone agonist; $\mathrm{GnRH}$ ant: Gn-RH-antagonist; hCG: Human chorionic gonadotropin;

Ht\%: Hematocrite value; ICSI: Intra-cytoplasmic sperm injection; IL: Interleukin; IVF: In-vitro fertilization; KSA: Kingdom of Saudi Arabia; LH: Luteinizing hormone; MHz: Megahertz; MOD: Maximal ovarian diameter; mRNA: Messenger ribonucleic acid; OHSS: Ovarian hyperstimulation syndrome; PEDF: Pigment epithelium-derived factor; TLC: Total leucocytic count; TSH: Thyroid stimulating hormone; US: Ultrasound; VAS: Visual analogue scale; VEGF: Vascular endothelial growth factor
\end{abstract}

\section{Acknowledgements \\ Authors would like to thank our nursing staff who provided help for completion of data collection and also to acknowledge MSRA Scientific Teamwork, for revision and adjustment of this work (https:// www.facebook.com/MSRA-2017-Scientific-Organization-1826538560939267).}

\section{Funding}

The author(s) received no financial support for the research, authorship, and/ or publication of this article.

\section{Availability of data and materials}

The datasets used and/or analyzed during the current study were available from the corresponding author on reasonable request.

\section{Authors' contributions \\ KMS: Analysis, Manuscript Drafting, Acquisition of data, Critical Discussion, Management and Follow up of cases; HMA: Study Design, Manuscript Drafting, Acquisition and interpretation of data, Management and Follow up of cases; IIS: Management and Follow up of cases, Analysis and interpretation of data, Manuscript Revision; MFE: Management and Follow up of cases,Study Design, Analysis, Manuscript Drafting, Critical Discussion; AAM participated in the design of the study, performed the statistical analysis, and revised Manuscript critically for important intellectual content. All authors read and approved the final manuscript.}

\section{Ethics approval and consent to participate}

The study was approved by the Local Ethical Committee of Benha university Hospital (6-11-2014) and written informed consent was obtained from each participant before study. Trial registration (clinical trial.gov registration) NCT02823080 (retrospective) Initial Release 21-6-2016 Last Release 3-1-2017 Unique Protocol ID: Benha U Secondary IDs: kmsalama.

\section{Consent for publication}

Not applicable.

\section{Competing interests}

The authors declare that they have no competing interests.

\section{Publisher's Note}

Springer Nature remains neutral with regard to jurisdictional claims in published maps and institutional affiliations.

Received: 1 April 2017 Accepted: 3 November 2017

Published online: 13 November 2017

\section{References}

1. Tang H, Mourad S, Zhai SD, Hart RJ. Dopamine agonists for preventing ovarian hyperstimulation syndrome. Cochrane Database Syst Rev. 2016;11:CD008605.

2. Ashrafi M, Bahmanabadi A, Akhond MR, Arabipoor A. Predictive factors of early moderate/severe ovarian hyperstimulation syndrome in non-polycystic ovarian syndrome patients: a statistical model. Arch Gynecol Obstet. 2015; 292(5):1145-52.

3. Kdous M, M'Solly S, Zhioua F, Meriah S. Use of GnRh antagonist (Cetrorelix) in controlled ovarian hyperstimulation in women with polycystic ovary disease. Tunis Med. 2008;86(12):1060-5.

4. Martínez F, Clua E, Santmartí P, Boada M, Rodriguez I, Coroleu B. Randomized, comparative pilot study of pituitary suppression with depot leuprorelin versus cetrorelix acetate $3 \mathrm{mg}$ in gonadotropin stimulation protocols for oocyte donors. Fertil Steril. 2010;94(6):2433-6.

5. Depalo R, Jayakrishan K, Garruti G, Totaro I, Panzarino M, Giorgino F. GnRH agonist versus $\mathrm{GnRH}$ antagonist in in vitro fertilization and embryo transfer (IVF/ET). Reprod Biol Endocrinol. 2012;10:26.

6. Turan GA, Eskicioglu F, Sivrikoz ON, Cengiz H, Adakan S, Gur EB, Tatar S, Sahin N, Yilmaz O. Myo-inositol is a promising treatment for the prevention of ovarian hyperstimulation syndrome (OHSS): an animal study. Arch Gynecol Obstet. 2015;292(5):1163-71.

7. Şahin N, Apaydın N, Töz E, Sivrikoz ON, Genç M, Turan GA, Cengiz H, Eskicioğlu F. Comparison of the effects of letrozole and cabergoline on vascular permeability, ovarian diameter, ovarian tissue VEGF levels, and blood PEDF levels, in a rat model of ovarian hyperstimulation syndrome. Arch Gynecol Obstet. 2015 Dec 21; [Epub ahead of print]

8. Turan GA, Eskicioglu F, Sivrikoz ON, Cengiz H, Gur EB, Tatar S, Sahin N, Yilmaz O. Prophylactic vitamin D supplementation in ovarian hyperstimulation syndrome: an animal study. Arch Gynecol Obstet. 2015; 292(2):421-7.

9. Kılıç N, Özdemir Ö, Başar HC, Demircan F, Ekmez F, Yücel O. Cabergoline for preventing ovarian hyperstimulation syndrome in women at risk undergoing in vitro fertilization/intracytoplasmic sperm injection treatment cycles: a randomized controlled study. Avicenna J Med. 2015;5(4):123-7.

10. Escárceǵa JA, Rodríguez R, Montemayor R, Batiza V, García G, Santos R, Hernández S, Galache P. Severe syndrome of ovarian hyperstimulation. Incidence, value of criteria of risk factors and preventive methods. Ginecol Obstet Mex. 1997;65:175-81.

11. Scott J, Huskisson EC. Graphic representation of pain. Pain. 1976;2:175-84.

12. Watcha MF, White PF. Postoperative nausea and vomiting. Its etiology, treatment, and prevention. Anesth. 1992;77:162-84.

13. Lainas TG, Sfontouris IA, Zorzovilis IZ, Petsas GK, Lainas GT, Kolibianakis EM. Management of severe early ovarian hyperstimulation syndrome by reinitiation of GnRH antagonist. Reprod BioMed Online. 2007;15:408-12.

14. Navot D, Bergh PA, Laufer N. Ovarian hyperstimulation syndrome in novel reproductive technologies: prevention and treatment. Fertil Streil. 1992;58:249.

15. Albano C, Smitz J, Camus M, Riethmüller-Winzen H, Van Steirteghem A, Devroey P. Comparison of different doses of gonadotropin-releasing hormone antagonist Cetrorelix during controlled ovarian hyperstimulation. Fertil Steril. 1997;67(5):917-22.

16. Bonilla-Musoles FM, Raga F, Castillo JC, Sanz M, Dolz M, Osborne N. High doses of $\mathrm{GnRH}$ antagonists are efficient in the management of severe ovarian hyperstimulation syndrome. Clin Exp Obstet Gynecol. 2009;36(2):78-81.

17. Hosseini MA, Mahdavi A, Aleyasin A, Safdarian L, Bahmaee F. Treatment of ovarian hyperstimulation syndrome using gonadotropin releasing hormone antagonist: a pilot study. Gynecol Endocrinol. 2012;28(11):853-5.

18. Lainas GT, Kolibianakis EM, Sfontouris IA, Zorzovilis IZ, Petsas GK, Lainas TG, Tarlatzis BC. Pregnancy and neonatal outcomes following luteal GnRH antagonist administration in patients with severe early OHSS. Hum Reprod. 2013;28(7):1929-42. 
19. Hebisha SA, Aboelazm BA, Sallam HN. GnRH antagonist Cetrorelix administration before hCG for protection of ovarian Hyperstimulation syndrome. J Obstet Gynaecol India. 2017;67(4):270-4.

20. Lainas GT, Kolibianakis EM, Sfontouris IA, Zorzovilis IZ, Petsas GK, Lainas TG, Tarlatzis BC. Serum vascular endothelial growth factor levels following luteal gonadotrophin-releasing hormone antagonist administration in women with severe early ovarian hyperstimulation syndrome. BJOG. 2014;121(7):848-55.

21. Jakimiuk AJ, Fritz A, Grzybowski W, Walecka I, Lewandowski P. Diagnosing and management of iatrogenic moderate and severe ovarian hyperstymulation syndrome (OHSS) in clinical material. Folia Histochem Cytobiol. 2007:45(Suppl 1):S105-8.

22. Bar-Joseph H, Ben-Ami I, Ron-El R, Shalgi R, Chuderland D: Pigment epithelium-derived factor exerts antioxidative effects in granulosa cells. Fertil Steril. 2014; 102(3):891-898.e3.

23. Chuderland D, Ben-Ami I, Bar-Joseph H, Shalgi R. Role of pigment epitheliumderived factor in the reproductive system. Reproduction. 2014;148(4):R53-61.

24. Miller I, Chuderland D, Ron-El R, Shalgi R, Ben-Ami I. GnRH agonist triggering modulates PEDF to VEGF ratio inversely to hCG in Granulosa cells. J Clin Endocrinol Metab. 2015;100(11):E1428-36.

25. Bar-Joseph H, Ben-Ami I, Ron-El R, Shalgi R, Chuderland D. Pigment epithelium-derived factor regulation by human chorionic gonadotropin in granulosa cells. Reproduction. 2016;151(2):179-85.

26. Lunger $F$, Vehmas AP, Fürnrohr BG, Sopper $S$, Wildt L, Seeber B. Opiate receptor blockade on human granulosa cells inhibits VEGF release. Reprod BioMed Online. 2016;32(3):316-22.

27. Orvieto R, Dratviman-Storobinsky O, Cohen Y. Interleukin-2 production by cultured human Granulosa cells. Am J Reprod Immunol. 2015;74(5):392-7.

28. Taskin MI, Topcu O, Yay A, Erken G, Balcioğlu E, Adali E, Hismiogulları AA. Prevention of ovarian hyperstimulation syndrome in a rat model: comparison of the efficacy of tocilizumab with that of ranibizumab, cabergoline, and a gonadotropin-releasing hormone antagonist. Gynecol Endocrinol. 2015;31(12):949-54.

29. Delabaere A, Tran X, Jardon K, Pouly JL, Bourdel N. Spontaneous ovarian hyperstimulation syndrome in a pregnancy with hypothyroidism. Gynecol Obstet Fertil. 2011:39(3):e64-7.

30. Langroudi RM, Amlashi FG, Emami MH. Ovarian cyst regression with levothyroxine in ovarian hyperstimulation syndrome associated with hypothyroidism. Endocrinol Diabetes Metab Case Rep. 2013;2013:130006.

31. Orkunoglu-Suer F, Harralson AF, Frankfurter D, Gindoff P, O'Brien TJ. Targeted single molecule sequencing methodology for ovarian hyperstimulation syndrome. BMC Genomics. 2015;16:264.

32. Blumenfeld Z. Why more is less and less is more when it comes to ovarian stimulation. J Assist Reprod Genet. 2015;32(12):1713-9.

\section{Submit your next manuscript to BioMed Central and we will help you at every step:}

- We accept pre-submission inquiries

- Our selector tool helps you to find the most relevant journal

- We provide round the clock customer support

- Convenient online submission

- Thorough peer review

- Inclusion in PubMed and all major indexing services

- Maximum visibility for your research

Submit your manuscript at www.biomedcentral.com/submit

) Biomed Central 